\title{
Ultra-violet spectra studies of photodegradation of PVC films in presence of Fe(III) chelate complex
}

\author{
Emad Yousif a, Raghad Haddad a, Ameer Abbas Ameer b,* and Yip-Foo Win c \\ a Department of Chemistry, College of Science, Al-Nahrain University, Baghdad, 64021, Iraq \\ b College of Engineering and Computing, Al-Ghurair University, Dubai, United Arab Emirates \\ c Department of Chemical Science, Faculty of Science, University Tunku Abdul Rahman, Perak Campus, Jalan University, Bandar Barat, 31900 Kampar, Perak, \\ Malaysia
}

*Corresponding author at: College of Engineering and Computing, Al-Ghurair University, Dubai, United Arab Emirates. Tel.: +971.04.4200223. Fax: +971.04.4200226. E-mail address: ameer.albayati@gmail.com (A.A. Ameer).

\section{ARTICLE INFORMATION}

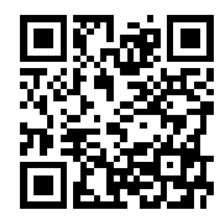

DOI: 10.5155/eurjchem.5.4.607-611.1102

Received: 09 June 2014

Received in revised form: 07 July 2014

Accepted: 10 July 2014

Online: 31 December 2014

\section{KEYWORDS}

\section{PVC}

Triazole

UV-light

Fe(III) complex

Photochemistry

Photodegradation

\section{Introduction}

Poly(vinyl chloride) is a thermoplastic and the third largest production polymer in the world [1]. However, PVC suffers from poor thermal and light stability. It undergoes rapid autocatalytic dehydrochlorination upon exposure to heat and light during its molding and use, respectively [2]. As a result, conjugated polyene sequences are formed from the beginning of the reaction, and they give rise to discoloration of the polymer and seriously change its physical properties [3]. The low cost and the good performance of poly(vinyl chloride) products have increased the utilization of this polymer in building, mainly in exterior application, such as window profiles, cladding structure, and siding [4].

In recent years, the use of polymeric materials has rapidly increased but it is well established that rapid photodegradation of these materials is probable when they are exposed to natural weathering [5-7]. A wide variety of synthetic and naturally occurring high polymers absorb solar ultraviolet radiation and undergo photolytic, photooxidative, and thermooxidative reactions that result in the degradation of the material [8-9]. To ensure the weather ability of these materials, the PVC needs to be compounded and processed properly using suitable additives, leading to complex material whose behavior and properties are quite different from the PVC by itself [10].

Photooxidation of organic materials is a major cause of irreversible deterioration for a large number of substances. It is responsible for the loss of physical properties of plastics [11] yellowing, loss of gloss and mechanical properties (cracking), of polymers and other problems associated with UV light [12-15]. It is well known that all commonly used plastics degrade under the influence of sunlight.

All synthetic polymers require stabilization against the adverse effects; it became necessary to find ways to prevent, or to reduce, the damage caused by the environmental parameters such as light, air and heat. That is why the photostability of polymers is one of the most important considerations for application.

The photostabilization of polymers involves the retardation or elimination of photochemical process in polymers and plastics that occur during irradiation. The following stabilizing systems have been developed which depend on the action of stabilizer: (a) light screeners, (b) UV absorbers, (c) excited state quenchers, (d) peroxide decomposers and (e) radical scavengers [16-19]. 
In this paper, we report the designing of compound that used as a photo inducer for degradation process, and was studied with different concentration of additive in PVC films.

\section{Experimental}

\subsection{Materials and methods}

All the reagents, starting materials as well as solvents were purchased commercially and used without any further purification. The infrared spectra (FT-IR) were recorded by using FTIR 8300 Shimadzu spectrophotometer in the frequency range of $4000-200 \mathrm{~cm}^{-1}$. The ultraviolet-visible spectra (UVVIS) were recorded using Shimadzu UV-VIS 160 A-Ultra-violet spectrophotometer in the range of 200-1100 $\mathrm{nm}$. Morphological study was recorded by using MEIJI TECHNO microscope, (Japan).

\subsection{Synthesis of $\mathrm{Fe}(\mathrm{L})_{3}$ complexes}

A complex of Fe(III) with 4-amino-5-(pyridyl)-4H-1,2,4triazole-3-thiol, prepared by the method previously described by Haddad et al., [20] (Figure 1).

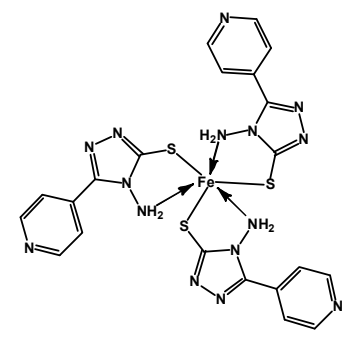

Figure 1. Structure of $\mathrm{Fe}(\mathrm{L})_{3}$ complex.

\subsection{Film preparation}

Polyvinyl chloride dissolved with Fe(III) complex in THF solvent to form PVC films of 5\% (40 $\mu \mathrm{m})$ thickness containing different concentrations $(0.01,0.02,0.03,0.04$, and $0.05 \mathrm{~g})$ of the complex by weight. Their thickness was measured by a micrometer type 2610 A, Germany. The films were prepared by evaporation technique at room temperature for 24 hours, to remove the possible residual solvent [21].

\subsection{Irradiation experiment}

\subsubsection{Accelerated testing technique}

UV-Light was used for irradiation of PVC films, giving wavelength range between ( 250 to $380 \mathrm{~nm}$ ) and the maximum

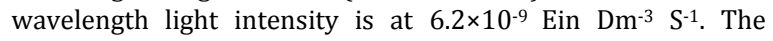
polymer film samples were fixed parallel to each other and the lamp of the UV incident radiation is vertical on the samples. The distance between the polymer films and the source was $(10 \mathrm{~cm})$. The polymer film samples were vertically fixed parallel to the lamps to make sure that the UV incident radiation is perpendicular to the samples. The irradiated samples were rotated from time to time to ensure that the intensity of light incident on all samples is the same [22,23].

\subsubsection{Photodegradation measuring methods}

\subsubsection{Measuring the photodegradation rate of polymer films using ultraviolet-visible spectrophotometer}

The ultraviolet-visible spectrophotometer type Shimadzu UV-VIS 160 was used to measure the changes in the UV-visible spectrum during irradiation time for each compound at maximum absorption band $\left(\lambda_{\max }\right)$. The absorption spectrum was measured in the range of $200-400 \mathrm{~nm}$, and the $\lambda_{\max }$ at each absorption was also recorded for different irradiation times.

The infinite irradiation time was considered and the infinite absorption $\left(\mathrm{A}_{\infty}\right)$ was assumed to be after the infinite irradiation time. To determine the photodegradation rate constant for photostabilizer $\left(K_{\mathrm{d}}\right)$, the first order equation was used:

$\operatorname{Ln}(\mathrm{a}-\mathrm{x})=\operatorname{Ln} \mathrm{a}-K_{\mathrm{d}} \cdot \mathrm{t}$

where "a" represents the stabilizer concentration before irradiation and " $x$ " represents the change in stabilizer concentration after irradiation time $(\mathrm{t})$. If $\mathrm{A}_{0}$ represents the absorption intensity of the polymer film containing stabilizer before irradiation and $A_{t}$ represents the absorption intensity after $t$ time of irradiation, then:

$\mathrm{a}=\mathrm{A}_{0}-\mathrm{A}_{\infty}$

$\mathrm{x}=\mathrm{A}_{0}-\mathrm{A}_{\mathrm{t}}$

$\mathrm{a}-\mathrm{x}=\mathrm{A}_{0}-\mathrm{A}_{\infty}-\mathrm{A}_{0}+\mathrm{A}_{\mathrm{t}}=\mathrm{A}_{\mathrm{t}}-\mathrm{A}_{\infty}$

Substitution of a and $(a-x)$ in equation (1) to give:

$\operatorname{Ln}\left(A_{t}-A_{\infty}\right)=\operatorname{Ln}\left(A_{o}-A_{\infty}\right)-K_{d} \cdot t$

Thus a plot of $\ln \left(A_{t}-A_{\infty}\right)$ versus irradiation time (t) gives straight line with a slope equal $\left(K_{\mathrm{d}}\right)$ which indicates that photodecomposition of the additives is first order.

\section{Results and discussion}

The complex of Fe(III) with 4-amino-5-(pyridyl)-4H-1,2,4triazole-3-thiol was used as an additive for the photodegradation of PVC films of thickness $40 \mu \mathrm{m}$ with different concentrations of the complex. The carbonyl groups generated during the photooxidation [24-25] process of polymer, extend the polymer film absorption to longer wavelengths. Figure 2 details the mechanism of photodegradation of PVC in the presence of oxygen. These groups absorb light when they irradiated with light of wavelength between (200-700 nm) and activated to the singlet and triplet excited states which enhances various successive photooxidation reactions [26]. The photodegradations during different irradiation times were followed by observing changes in carbonyl and hydroxyl peaks. The position of carbonyl absorption is assigned at $1730 \mathrm{~cm}^{-1}$, and hydroxyl is assigned in $3400 \mathrm{~cm}^{-1}$ [27-29]. Then carbonyl (I $\mathrm{CO}$ ) and hydroxyl ( $\mathrm{IOH}_{\mathrm{H}}$ indices were calculated by comparison of the FT-IR absorption peak at 1730 and $3400 \mathrm{~cm}^{-1}$ with reference peak at $1450 \mathrm{~cm}^{-1}$, respectively. This method is called band index method which includes:

$\mathrm{Is}=\frac{\mathrm{As}}{\mathrm{Ar}}$

where "As" = Absorbance of peak under study, "Ar" = Absorbance of reference peak, and "Is" = Index of the group under study. Actual absorbance, the difference between the absorbance of base line and top peak (A top peak-A base line), is calculated using the Base Line method. Ultraviolet radiations are known to have deleterious effects on most industrial polymers inducing chemical modification and scission of polymer chain, which ultimately lead to an undesirable loss of the mechanical and surface properties of the irradiated material. Photodegradation of PVC causes discoloration (yellowing), cross-linking, and chain scission due to oxidation and effect of UV light and heat [30-31]. 


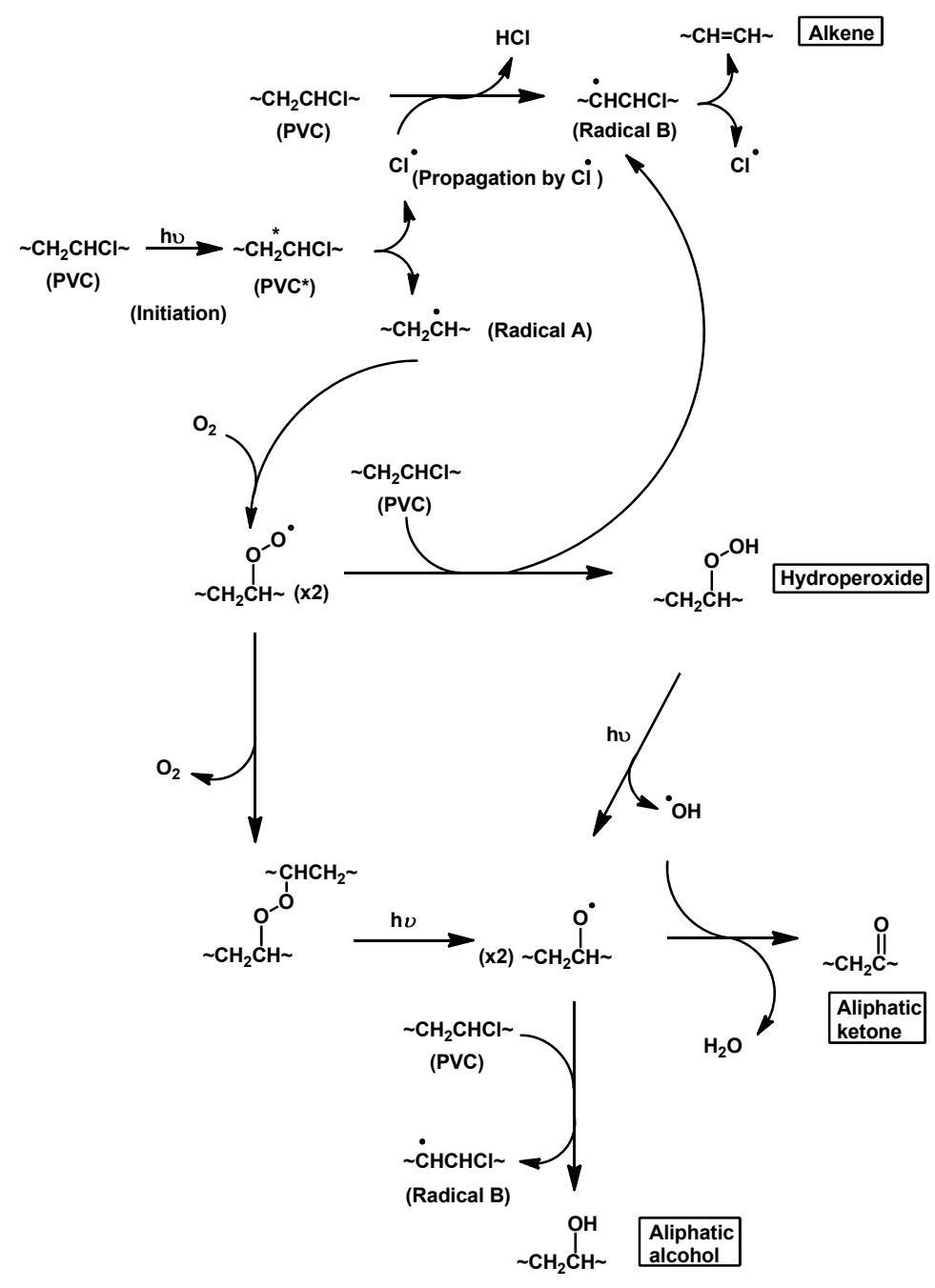

Figure 2. Photooxidation reaction scheme of PVC.

UV light induces the production of radicals by oxidation. The prepared complexes were used as photo induced for PVC films comparing with PVC blank. The additives used in this study were chosen to be completely soluble in polymer solvent, THF. The additive concentration plays an important role in photodegradation and photostabilization of polymers. So many investigators have studied the effect of additives concentration in photodegradation and photostabilization of polymers [32]. In this work, it has been noticed that the additives used photodecomposed during the photolysis. Thus, the photo decomposition rate constant $\left(K_{\mathrm{d}}\right)$ was calculated. The $K_{\mathrm{d}}$ values were computed using the UV spectra changes of PVC films thickness $40 \mu \mathrm{m}$ containing $0.5 \%(w: w)$ from additives. The plot of irradiation time versus $\ln \left(A_{t}-A_{\infty}\right)$, gives straight line which indicate primarily the first order reaction. The slope equal to the decomposition rate constant $K_{\mathrm{d}}$. Figures 3 to 8 show the variation of $\ln \left(A_{t}-A_{\infty}\right)$ with irradiation time for all additives in PVC films at $\lambda=365 \mathrm{~nm}$. The values of the first order rate constant of all the modified polymers films $\left(K_{\mathrm{d}}\right)$ calculated by the same way and shown in Table 1 . The photodegration always possess high $K_{\mathrm{d}}$ values, which mean that these modified polymers degradated towards UV light. On the other side, there is another method for characterization degradation reaction; it is the measurement of the quantum yield of the chain scission $\left(\Phi_{\mathrm{cs}}\right)[33]$.
Table 1. Photodecomposition rate constant $\left(K_{\mathrm{d}}\right)$ of PVC films with different concentration from additive.

\begin{tabular}{ll}
\hline Sample & $\boldsymbol{K}_{\mathbf{d}}$ \\
\hline PVC blank & $1.6240 \times 10^{-3}$ \\
$\mathrm{PVC}+0.01 \mathrm{Fe}(\mathrm{L})_{3}$ & $1.9846 \times 10^{-3}$ \\
$\mathrm{PVC}+0.02 \mathrm{Fe}(\mathrm{L})_{3}$ & $3.7497 \times 10^{-3}$ \\
$\mathrm{PVC}+0.03 \mathrm{Fe}(\mathrm{L})_{3}$ & $4.3349 \times 10^{-3}$ \\
$\mathrm{PVC}+0.04 \mathrm{Fe}(\mathrm{L})_{3}$ & $4.9549 \times 10^{-3}$ \\
$\mathrm{PVC}+0.05 \mathrm{Fe}(\mathrm{L})_{3}$ & $5.1246 \times 10^{-3}$ \\
\hline
\end{tabular}

$\mathrm{PVC}+0.05 \mathrm{Fe}(\mathrm{L})_{3} \quad 5.1246 \times 10^{-3}$

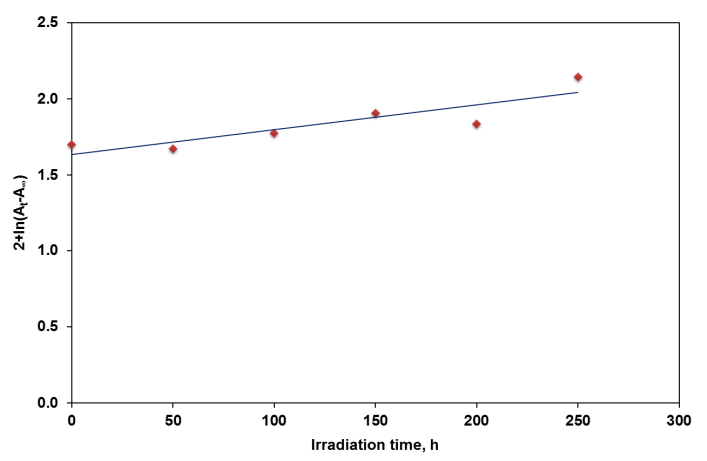

Figure 3. Variation of $\ln \left(A_{t}-A_{\infty}\right)$ with irradiation time of $P V C+0.00 \mathrm{Fe}(L)_{3}$ film (Blank). 


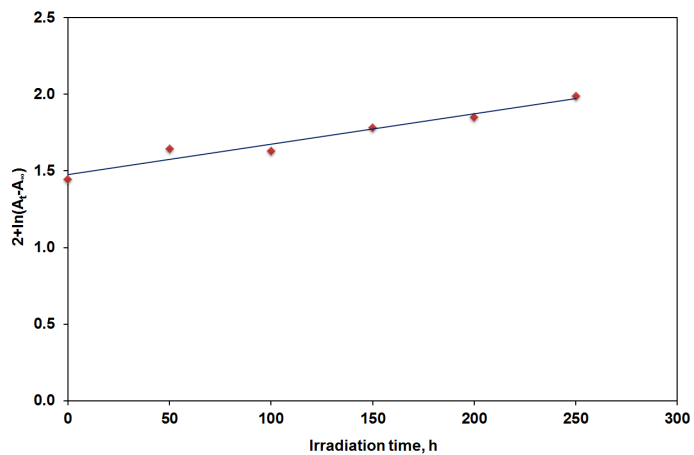

Figure 4. Variation of $\ln \left(A_{t}-A_{\infty}\right)$ with irradiation time of $\mathrm{PVC}+0.01 \mathrm{Fe}(\mathrm{L})_{3}$ film.

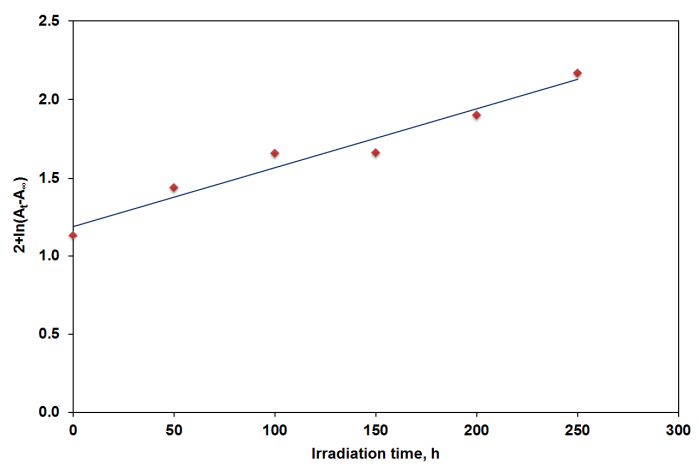

Figure 5. Variation of $\ln \left(A_{t}-A_{\infty}\right)$ with irradiation time of $P V C+0.02 \mathrm{Fe}(L)_{3}$ film.

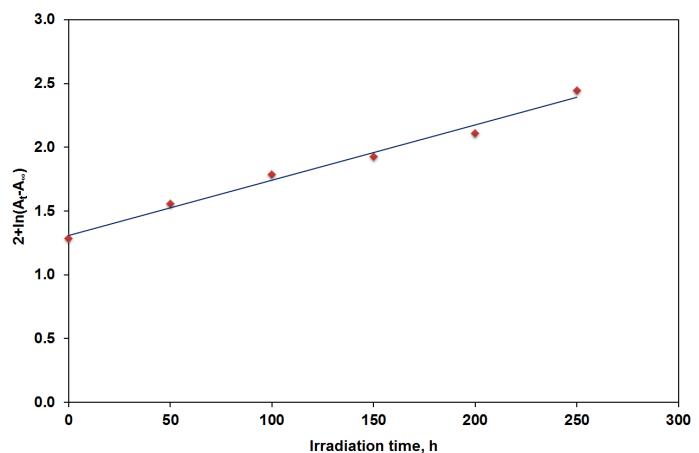

Figure 6. Variation of $\ln \left(A_{t}-A_{\infty}\right)$ with irradiation time of $\mathrm{PVC}+0.03 \mathrm{Fe}(\mathrm{L})_{3}$ film.

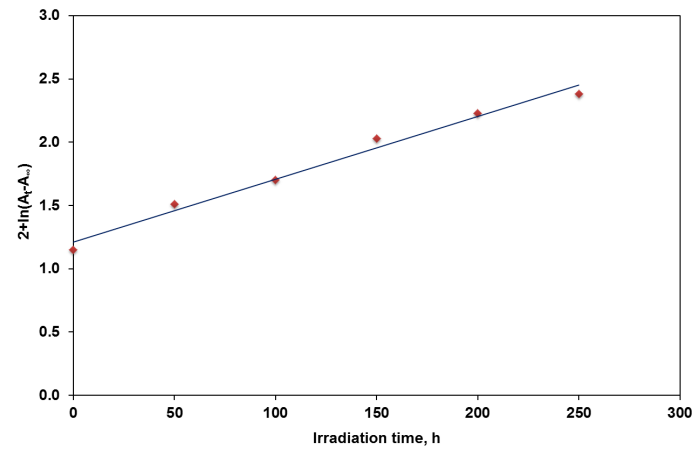

Figure 7. Variation of $\ln \left(\mathrm{A}_{\mathrm{t}}-\mathrm{A}_{\infty}\right)$ with irradiation time of $\mathrm{PVC}+0.04 \mathrm{Fe}(\mathrm{L})_{3}$ film.

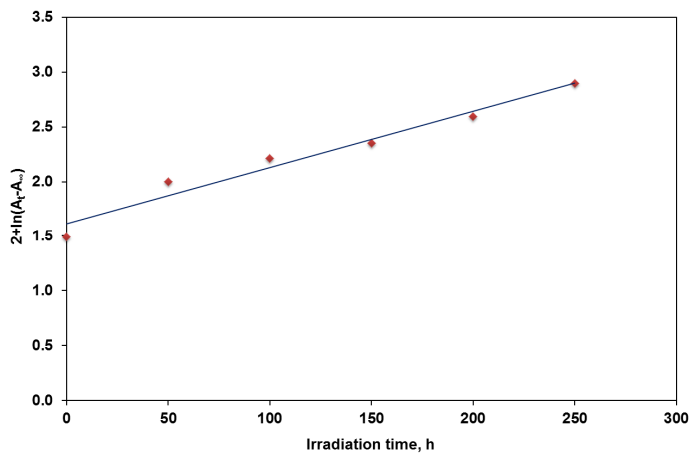

Figure 8. Variation of $\ln \left(A_{t}-A_{\infty}\right)$ with irradiation time of $P V C+0.05 \mathrm{Fe}(\mathrm{L})_{3}$ film.

The quantum yield for chain scission was calculated for PVC films of modified polymers by using this relation:

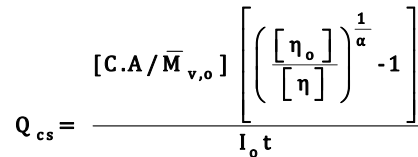

where, $\mathrm{C}=$ concentration, $\mathrm{A}=$ Avogadro's number, $\mathrm{M}_{\mathrm{V}, \mathrm{O}}=$ the initial viscosity-average molecular weight, $\left[\eta_{\mathrm{o}}\right]=$ Intrinsic viscosity of polymer before irradiation, $[\eta]=$ Intrinsic viscosity of polymer after irradiation, $\alpha=$ Exponent in the relation: $[\eta]=$ K. $\mathrm{M}^{\alpha}, \mathrm{I}_{\mathrm{o}}=$ Incident intensity. The $\Phi_{\mathrm{cs}}$ values for these polymers are tabulated in Table 2 . The $\Phi_{\mathrm{cs}}$ values for modified PVC films are more than that of PVC (blank)

Table 2. Quantum yield ( $\left.\Phi_{\mathrm{cs}}\right)$ for the chain scission for PVC films $(40 \mu \mathrm{m})$ thickness, with and without different concentration from additive, after 200 $\mathrm{h}$ irradiation time.

\begin{tabular}{ll}
\hline Additives & Quantum yield \\
\hline PVC (blank) & $3.180 \times 10^{3}$ \\
$\mathrm{PVC}+0.01 \mathrm{Fe}(\mathrm{L})_{3}$ & $4.590 \times 10^{3}$ \\
$\mathrm{PVC}+0.02 \mathrm{Fe}(\mathrm{L})_{3}$ & $4.790 \times 10^{3}$ \\
$\mathrm{PVC}+0.03 \mathrm{Fe}(\mathrm{L})_{3}$ & $1.047 \times 10^{4}$ \\
$\mathrm{PVC}+0.04 \mathrm{Fe}(\mathrm{L})_{3}$ & $1.464 \times 10^{4}$ \\
$\mathrm{PVC}+0.05 \mathrm{Fe}(\mathrm{L})_{3}$ & $3.485 \times 10^{4}$ \\
\hline
\end{tabular}

\section{Conclusion}

Addition of the complex tris(4-amino-5-(pyridyl)-4H-1,2,4triazole-3-thiol) Fe(III) to polyvinyl chloride (PVC) films in different concentrations have successfully worked as photoinducer for degradation process for PVC films. The photooxidation rate increased with increasing additive concentration.

\section{Acknowledgements}

The authors would like to thank Al-Nahrain University, AlGhurair University and University Tunku Abdul Rahman for financial support as well as technical assistance and facilities.

\section{References}

[1]. Allsopp, M.; Vianello, G. Ullmann's Encyclopedia of Industria Chemistry, Wiley-VCH. Weinheim, 2012.

[2]. Yousif, E. Photostabilization of thermoplastic polymers, Lambert Academic Publishing, Germany, 2012.

[3]. Pimentel, R.; Ferraria, A.; Botelho, A. Polym Test 2008, 27, 743-751.

[4]. Andrady, A.; Hamid, S.; Hu, X.; Torikai, A. J. Photoch. Photobio. B 1998 46, 96-103.

[5]. Hamid, H. Handbook of Polymer Degradation, Environmental Science and Pollution, Marcel Dekker Inc., New York, 2000. 
[6]. Rabek, F. Mechanisms of photophysical and photochemical reactions in polymer: Theory and practical application, John Wiley and Sons, New York, 1987.

[7]. Bottino, A.; Cinquegrani, R.; Di Pasquale, G.; Leonardi, L.; Pollicino, A. Polym. Test. 2003, 12, 405-411.

[8]. Scott, G. Polym. Degrad. Stabil. 2000, 68, 1-7.

[9]. Valkoa, L.; Kleinb, E.; Kovarikb, P.; Simonb, P. Eur. Polym. J. 2001, 37, 1123-1133.

[10]. Ayako, T.; Hirose, H. Polym. Degrad. Stabil. 1999, 63, 441-452.

[11]. Grassie, N.; Scott, G. Polymer Degradation and Stabilization, Cambridge University Press, London, 1985.

[12]. Galdi, A.; Foltis, P.; Shah, A. US patent. Application, 2010, 2010118415.

[13]. Pospisil, J.; Pilar, J.; Billingham, C.; Marek, A.; Horak, Z.; Nespurek, S. Polym. Degrad. Stabil. 2006, 91, 417-422.

[14]. Bojinov, B.; Grabchev, K. Polym. Photochem. Photobiol. 2005, 172, 308315.

[15]. Goldshtein, J.; Margel, S. Colloid Polym. Sci. 2011, 289, 1863-1874.

[16]. Yousif, E.; Salimon, J.; Salih, N. J. Appl. Polym. Sci. 2012, 125, 19221927.

[17]. Yousif, E.; Salimon, J.; Salih, N. J. Saudi. Chem. Soc. 2011, 16(3), 299306.

[18]. Yousif, E.; Haddad, R. SpringerPlus 2013, 2, 398-460.

[19]. Yousif, E.; Haddad, R.; Ahmed, A. Photodegradation and Photostabilization of Polystyrene, Lambert Academic Publishing, Germany, 2013

[20]. Haddad, R.; Yousif, E.; Ahmed, A. SpringerPlus 2013, 2, 510-516.

21]. Yousif, E.; Salih, N.; Salimon, J. J. Appl. Poly. Sci. 2011, 120, 2207-2214.

[22]. Yousif, E.; Salimon, J.; Salih, N. Malaysian J. Anal. Sci. 2011, 15(1), 8192.

[23]. Yousif, E.; Aliwi, S.; Ameer, A.; Ukal, J. Turk. J. Chem. 2009, 33, 339-410.

[24]. Mori, F.; Koyama, M.; Oki, Y. Angew. Makromol. Chem. 1979, 75, 113122.

[25]. Rabie, S.; Ahmed, A.; Sabaa, M.; El-Ghaffar, M. J. Ind. Eng. Chem. 2013, 19, 1869-1878.

[26]. Cooray, B.; Scott, G. J. Eur. Polym. 1980, 169(16), 177-189.

[27]. Naif, O.; Salih, H. Tikrit J. Pure Sci. 2011, 16(4), 1813-1662.

[28]. Rabek, J.; Sanetra, J. Macromol. 1986, 19, 1679-1684.

[29]. Yousif, E.; Salimon, J.; Salih, N. Arabian J. Chem. 2014, 7, 306-311.

[30]. Rabek, F.; Polymer photodegradation of polymers: Physical characteristic and applications, Springer-Verlag. Berlin, 1996.

[31]. Kiatkamjornwong, S.; Sonsuk, M.; Wittayapichet, S.; Prasassarakich, P.; Vejjanukroh, P. Polym. Degrad. Stab. 1999, 66, 323-334.

[32]. Abdelbagi, A. Sudan J. Basic Sci. 2008, 15, 39-50.

[33]. Al-Jibouri, M.; Al-Ameri, S.; Al-Jibouri, W.; Al-Souz, M. J. Assoc. Arab Univ. Basic Appl. Sci. 2013, 14, 67-74. 